Tserkovniuk R.G., Gozhenko A.I., Korolyshyn T.A., Lomeyko S.M., Fil V.M., Anchev A.S., Zukow W., Yanchij R.I., Popovych I.L. Relationships between geomagnetic Ap-index and EEG parameters in patients with dysfunction of the neuroendocrine-immune complex. Journal of Education, Health and Sport. 2021;11(8):536-552. eISSN 2391-8306. DOI http://dx.doi.org/10.12775/JEHS.2021.11.08.060 https://apcz.umk.pl/czasopisma/index.php/JEHS/article/view/JEHS.2021.11.08.060 https://zenodo.org/record/5856203

\footnotetext{
The journal has had 5 points in Ministry of Science and Higher Education parametric evaluation. § 8. 2) and § 12. 1. 2) 22.02.2019. (c) The Authors 2021

This article is published with open access at Licensee Open Journal Systems of Nicolaus Copernicus University in Torun, PolandOpen Access. This article is distributed under the terms of the Creative Commons Attribution Noncommercial License which permits any noncommercial use, distribution, and reproduction in any medium,provided the original author (s) and source are credited. This is an open access article licensed under the terms of the Creative Commons Attribution Non commercial license Share

alike.(http://creativecommons.org/licenses/by-nc-sa/4.0/) which permits unrestricted, non commercial use, distribution and reproduction in any medium, provided the work is properly cited.The authors declare that there is no conflict of interests regarding the publication of this paper.

Received: 10.08.2021. Revised: 20.08.2021. Accepted: 30.08.2021.
}

\title{
Relationships between geomagnetic Ap-index and EEG parameters in patients with dysfunction of the neuroendocrine-immune complex
}

\author{
R.G. Tserkovniuk ${ }^{1}$, A.I. Gozhenko ${ }^{1}$, T.A. Korolyshyn ${ }^{1,2,3}$, S.M. Lomeyko ${ }^{4}$, \\ V.M. Fil ${ }^{5}$, A.S. Anchev', W. Zukow ${ }^{6 *}$, R.I. Yanchij ${ }^{2}$, I.L. Popovych ${ }^{1,2}$ \\ ${ }^{1}$ Ukrainian Research Institute of Medicine for Transport, Odesa, Ukraine \\ ${ }^{2} \mathrm{OO}$ Bohomolets' Institute of Physiology of NAS, Kyïv, Ukraine \\ ${ }^{3}$ Clinical sanatorium "Moldova", Truskavets', Ukraine \\ ${ }^{4}$ Danylo Halyts'kyǐ National Medical University, L’viv, Ukraine \\ ${ }^{5}$ Ivan Franko Pedagogical University, Drohobych, Ukraine \\ ${ }^{6}$ Nicolaus Copernicus University, Torun, Poland \\ *w.zukow@,wp.pl
}

\begin{abstract}
Background. Recently, on the example of two cohort of patients, we found that disturbances of the geomagnetic field cause a significant immediate modulating effect on the level of immune parameters in the blood. The data available in the literature give grounds for assumptions about the direct effect of disturbances of the geomagnetic field on immunocytes, and indirectly, through immunotropic neurotransmitters and hormones. Our hypothesis is as follows. Disturbances of the geomagnetic field are perceived by acupuncture points (APs). The information obtained is transmitted to neurons and endocrinocytes, the mediators of which, in turn, affect immunocytes. The purpose of this study is to test this hypothesis.

Methods. The object of observation were 21 men (24-63 y) and 20 women (30-72 y) with neuroendocrine-immune complex dysfunction. Each patient was tested twice with an interval of 4 days. We recorded the ongoing electroencephalogram (EEG). Retrospectively we recorded the geomagnetic Ap-Index on the day of testing and during the previous 7 days, using resource https://www.spaceweatherlive.com/.

Results. The canonical correlation between Ap-indices for 7 days before and on the day of testing, and EEG parameters is 0,886; immunity parameters is 0,921. In turn, the immune parameters are closely related to the EEG parameters $(\mathrm{R}=0,944)$.
\end{abstract}


Conclusion. Disturbances of the geomagnetic field (Ap-index) causes a significant immediate modulating effect on the parameters of immunity as well as EEG, apparently through acupuncture points as polymodal receptors of the ecoceptive sensitivity system.

Key words: geomagnetic Ap-index, acupuncture points, EEG, immunity, relationships, humans.

\section{Introduction}

Recently, on the example of two cohort of patients, we found that disturbances of the geomagnetic field cause a significant immediate modulating effect on the level of immune parameters in the blood [1,2]. The data available in the literature give grounds for assumptions about the direct effect of disturbances of the geomagnetic field on immunocytes, and indirectly, through immunotropic neurotransmitters and hormones.

Back in 1990, Limansky [3] hypothesized acupuncture points (AP) as polymodal receptors of the ecoceptive sensitivity system. In the process of hypothesis development in 2003 an existence of separate functional system of regulation of electromagnetic balance of organism has been substantiated and a working conception of light therapy has been formulated [4].

Our hypothesis is as follows. Disturbances of the geomagnetic field are perceived by APs. The information obtained is transmitted to neurons and endocrinocytes, the mediators of which, in turn, affect immunocytes. The purpose of this study is to test this hypothesis.

\section{Methods}

Participants. The object of observation were 21 men $(24-63 ; 44 \pm 12$ y) and 20 women (30-72; $49 \pm 12 \quad$ y) with neuroendocrine-immune complex dysfunction: increased level of HRVsmarkers of sympathetic tone and decreased markers of vagal tone, moderate hypocortisolemia in both sexes and hypertestosteronemia in women, decreased parameters of phagocytosis by neutrophils of gram-negative and gram-positive bacteria as well as the level of T-helpers, but increased levels of NK- and B-lymphocytes, Igg $G$ and $M$. Each patient was examined twice with an interval of 4 days. Procedure / Test protocol / Slill test trial / Measure / Instruments. Observations were carried out on 09.06. and 13.06. 2015 (13 men and 3 women), 14.09. and 18.09. 2015 (1 man and 4 women), 27-28.03. and 04-05.04. 2018 (3 men and 7 women), 28.01 and 01.02. 2019 (4 men and 6 women). Retrospectively we recorded the geomagnetic Ap-Index, i.e. the average value of deviation of the geomagnetic field strength from normal in this region (range on Earth: 35-65 $\mu \mathrm{T}$ ) on the day of testing and during the previous 7 days, using a publicly available information resource https://www.spaceweatherlive.com/.

We recorded the ongoing EEG a hardware-software complex "NeuroCom Standard" (KhAI MEDICA, Kharkiv) monopolar in 16 loci (Fp1, Fp2, F3, F4, F7, F8, C3, C4, T3, T4, P3, P4, T5, T6, O1, O2) by $10-20$ international system, with the reference electrodes $\mathrm{A}$ and Ref tassels on the ears. The duration of the epoch was 25 sec.

Data collection and analysis. Among the options considered the average EEG amplitude $(\mu \mathrm{V})$, average frequency $(\mathrm{Hz})$, frequency deviation $(\mathrm{Hz})$, index $(\%)$, coefficient of asymmetry (\%) and absolute $(\mu \mathrm{V} 2 / \mathrm{Hz})$ and relative (\%) PSD of basic rhythms: $\beta(35 \div 13 \mathrm{~Hz}), \alpha(13 \div 8 \mathrm{~Hz}), \theta(8 \div 4$ $\mathrm{Hz})$ and $\delta(4 \div 0,5 \mathrm{~Hz})$ in all loci, according 
to the instructions of the device. In addition, calculated Laterality Index (LI) for PSD each Rhythm using formula:

LI, $\%=\Sigma[200 \bullet($ Right - Left $) /($ Right + Left)] $/ 8$

We calculated also for each locus Shannon's Entropy (h) of normalized PSD using Popovych's formula [5-7]:

$$
\begin{aligned}
& \mathrm{h}=-[\mathrm{PSD} \boldsymbol{\bullet} \log 2 \mathrm{PSD} \alpha+\mathrm{PSD} \beta \bullet \log 2 \\
& \mathrm{PSD} \beta+\mathrm{PSD} \theta \cdot \log 2 \mathrm{PSD} \theta+\mathrm{PSD} \delta \\
& \mathrm{PSD} \delta] / \log 2
\end{aligned}
$$

Statistical analysis. Results processed by using the software package "Statistica 64".

Compliance with Ethical Standards. Tests in patients are carried out in accordance with positions of Helsinki Declaration 1975, revised and complemented in 2002, and directive of National Committee on ethics of scientific researches. During realization of tests from all participants the informed consent is got and used all measures for providing of anonymity of participants.

\section{Results}

Analysis of the canonical correlation between Ap-Indices and EEG parameters (Table 1) shows the greatest sensitivity to geomagnetic perturbations of theta rhythm. Interestingly, on the day and on the eve of EEG registration geomagnetic disturbances have an inhibitory effect, while 3 and 4 days before it - activating.

Only after five days does the delta rhythm in the F8, T6, and Fp1 loci (activation) and the beta rhythm in general and the $\mathrm{O} 2$ locus in particular (suppression) respond to geomagnetic disturbances. An even longer stimulation lag was found for the beta rhythm at the F3 and $\mathrm{C} 3$ loci as well as the theta rhythm at the T5 locus, whereas the delta rhythm at the F7 locus is currently suppressed.
We would like to separately note the positive correlation of Entropy in locus O2 7 days before registration, which is inverted every other day.

It appears that neurons that generate different rhythms and that are projected onto different loci of the scalp respond to geomagnetic perturbation asynchronously, with a delay of 7 to 0,5 days and inversion of stimulation into inhibition.

According to the canonical correlation analysis, geomagnetic perturbations on the day of EEG registration and for seven days before it determines the EEG parameters by $79 \%$ (Table 2 and Fig. $1)$.

Color coding of rhythms immediately suggests the association of the limits of their ranges with Schuman's resonance harmonics: the first $(8,5$ and 7,83 $\mathrm{Hz}$ ) and second (14,7 and 14,1 Hz) (author's and experimentally established respectively). More about this in the discussion.

Collected patterns of coefficients of multiple correlation show the best congruence for the parameters of immunity and EEG, especially in the range from -5 to 0 days for testing (Fig. 2).

The visual impression is confirmed by the results of canonical correlation analysis, as a result of which two pairs of roots were formed.

The EEG Root of the first pair (Table 3) contains information about the PSD loci of the scalp, on which the nerve nuclei that generate delta, theta and beta rhythms are projected, which mainly have a suppressive effect on phagocytosis parameters, blood levels of B-lymphocytes and their secreted IgM as well as Tregulatory lymphocytes, which are present in the Immune Root. The opposite sign factor load on the level of 0-lymphocytes additionally reflects a decrease in the expression of at least CD22, CD4 and CD25 receptors. Naturally, this immunotropic 
effect is accompanied by a decrease in the Entropy of the Immunocytogram.

The degree of neurogenic immunomodulation is very significant: $89 \%$ (Fig. 3).

The EEG Root of the second pair (Table 4) is represented by another constellation of neural structures that mainly enhance serum Igg $A$ and $M$ levels, regulatory $\mathrm{T}$ lymphocytes level as well as $\mathrm{E}$. coli phagocytosis parameters.

The degree of neurogenic immunomodulation of this immune constellation is smaller, but still quite significant: $82 \%$ (Fig. 4).

\section{Discussion}

The presented results fit into the concept that Solar-induced fluctuations in the ambient geomagnetic field have been correlated with a wide range of biological effects [8], including changes in EEG [9-11] and HRV $[12,13]$ parameters in humans. Let's dwell in more detail on the research closest to ours in design. By the way, our study was not planned in advance, it is the result of a retrospective analysis of databases of previous projects, but carried out by the same performers on the same equipment. So, in essence, this is a truly double-blind study.

Our former compatriots Babayev and Allahverdiyeva [9], employing, like us, quantitative electroencephalographic (QEEG) technology, carried out investigations involving 27 functionally healthy females (permanent group), aged 20-40 years old. The EEG measurements (in 16 loci) were performed every day for each person at the same time of the day during geomagnetic quiet days. In the days with different levels of disturbances of geomagnetic conditions (few moderate and major geomagnetic storms: March 31, 2001; November 8-10, 2004; January 17-19, May
17, June 15, August 24, September 11-12, 2005; as well as some severe/extreme storms: July 2000; October-November 2003) the experiments were carried out several times.

Unfortunately, despite the declared quantitative approach to EEG analysis, the authors give only a qualitative description of the changes. The authors demonstrated conspicuous and specific changes in alpha and theta activity within the right hemispheres of normal subjects during major geomagnetic storms. There were almost no significant complaints about functional state in periods of weaklydisturbed geomagnetic conditions. Weak and severe geomagnetic storms affect the functional state of the human brain in a different way. It is established that weak and moderate geomagnetic storms exert stimulating influence while the strong disturbances of the geomagnetic conditions activate braking (inhibiting) processes. In the days of weak geomagnetic disturbances, no significant changes in the human brain activity were observed. Some negligible shifts, registered in several examinees, reflected an increased activity of mesodiencephalic structures usually observed during the activation of an organism. In comparison with the above-mentioned results, in the days with severe geomagnetic storms the human brain's activity is seriously disintegrated. The normal functioning of integrative non-specific systems, located within the limits of limbricreticular complex and responsible for creation of the relevant level of wakefulness, which is directed on realization of optimum current activity of an organism, is broken. The imbalance of activating and deactivating mechanisms also includes dysfunctions of ergo- and trophotropic over-segmentary centers. Babayev and Allahverdiyeva [9] concluded that changes in geomagnetic conditions 
mostly affect the activity of regulating systems, which are related to high cortical mechanisms of regulation and subcortical integrative apparatuses responsible for organization of routine activity of an organism, and for adaptation to changes of a physical environment.

For our part, we want to emphasize that theta and alpha rhythms were sensitive to geomagnetic disturbances, as in our study.

Previously Persinger and Richards [14] report here similar QEEG correlations, primarily involving the right hemisphere, during the much less intense periods of recent geomagnetic activity during the hiatus between Solar Cycle 23 and 24 in samples of healthy young adults. The magnitude of global (and local) geomagnetic variations was within the range (15-20 nT) correlated with enhanced vestibular experiences during partial sensory deprivation in healthy adults. Impressed, in our opinion, by the results of their Azerbaijani colleagues, and so strongly that they included the name of the country in the title of their article, the Canadians repeated the research of Azerbaijanis.

In Experiments I, Mulligan, Hunter and Persinger [10] analyzed the correlation between $\mathrm{Kp}$-indices for the interval between 1 July 2006 - 31 January 2008 (geomagnetic variations was within the range 20-25 nT) and QEEG parameters in healthy young people of both sexes. To discern the strength of effect a functional canonical correlation was completed between the beta power within the left parietal (P3) region $(r=-0,66)$ and the gamma power within the right frontal (F8) region $(r=-0,71)$ as dependent variables and the $\mathrm{Kp}$ value during the interval of the recording as the covariate. The equivalent multiple $\mathrm{R}$ was 0,73 .

In our observation, the correlation of Ap/PSD P3- $\beta$ was 0,10 and 0,02 on the day of registration, and on the eve of it 0,09 and $-0,03$ to relative and absolute PSD, respectively. We were not able to record the gamma rhythm, instead we recorded the EEG at 16 loci against 8 loci (F7, F8, T3, T4, P3, P4. O1, O2) in the cited study. And just in the C3 locus relative PSD- $\beta$ was positively correlated with Ap-index on the day of registration $(\mathrm{r}=0,30)$ and on the eve of it $(\mathrm{r}=0,24)$, while with the $\mathrm{C} 4$ locus the connections were weaker $(0,21$ and 0,19$)$.

Instead, our data are in principle consistent with the cited study on the inhibitory effect of geomagnetic field disturbances on PSD theta rhythm. The authors used an unconventional approach when calculating correlations between power values within each of the $1 \mathrm{~Hz}$ intervals and $\mathrm{Kp}$ values. Partial correlational analyses revealed the strongest correlation $(\mathrm{r}=-0,58)$ was between $\mathrm{Kp}$ values and power within the $8-8,9 \mathrm{~Hz}$ over the right [lateral] frontal (F8) lobe as well as the power within the 7-7,9 Hz band over the left parietal (P3) region $(r=-0,57)$. The equivalent multiple $R$ was 0,66 . In our study, the PSD of total theta band (4-7 Hz) connections for individual loci are much weaker, while the locus area is much larger, so that the canonical correlation between theta rhythm and Ap-index was almost similar. In addition, we found a correlation of Ap/PSD T6-alpha $(\mathrm{r}=-0,25)$.

In Experiments II by Mulligan et al, the results of which were published in the same paper [10], the correlation between QEEG parameters and Ap-indices for the interval between 9-20 March 2008 (geomagnetic variations was within the range 6-30 nT). For the geomagnetic correlations (Apindex), the strongest and most significant correlations for the wide-band were for gamma in the right [anterior] temporal (T4) lobe and theta in the right parietal (P4) lobe, similar to our data. For the successive $1-\mathrm{Hz}$ bands within the theta range, geomagnetic 
activity was correlated negatively with the $7-7,9 \mathrm{~Hz}$ band in the right frontal (F8) lobe while both the 3-3,9 Hz and 5-5,9 Hz bands were positively correlated within the right parietal (P4) lobe.

For the following correlation analysis, the authors for some reason used atmospheric power instead of Ap-index (correlation between them, however, is 0,93). As atmospheric power increased during the recordings power within the theta band decreased within the right frontal (F8) region $(r=-0,81)$ while there was general activation in the beta range over the right [anterior] temporal (T4) lobe $(\mathrm{r}=0,38)$ and in the gamma range for the temporal lobes of right $(\mathrm{r}=0,36)$ and left $(\mathrm{r}=0,36)$ hemispheres. Interestingly, that negative correlations for the $1-\mathrm{Hz}$ increments within the F8 theta (6$6,9 \mathrm{~Hz})$ and $((7-7,9 \mathrm{~Hz})$ are inverted into positive ones within the F8 $(5-5,9 \mathrm{~Hz}), \mathrm{F} 7$ (4-4,9 Hz), F7 (8-8,9 Hz) and P3 (4-4,9 Hz).

The Schumann-absorption model proposed by Cherry [15] and others presumes that maximal energy transfer between weak magnetic variations within the geomagnetic-ionospheric system [16] occur when the exogenous frequencies correspond with those measured from the brain by EEG. The peak absorption would involve the theta $(4-8 \mathrm{~Hz})$ and alpha $(8-13$ $\mathrm{Hz}$ ) bands, which include the base and first harmonic of the Schumann resonance [17]. Mulligan et al [10] reasoned that energy transfer could be inferred by more or less "instantaneous" increases and decreases in spectral power within the EEG theta band.

In contrast to the cited authors, we did not find much effect of geomagnetic activity on the right [lateral] frontal (F8) lobe. We also found similarly strong negative correlations for PSD theta rhythm in right parietal (P4) and right [anterior] temporal (T4) while left [lateral] frontal (F7) lobes as well as in both right (C4 and $\mathrm{T} 6)$ and left (C3 and Fp1) loci, which were not involved in the cited studies. In addition, PSD beta rhythm in locus C3 correlates positively with Ap-index. It is believed that the hippocampus is projected at the $\mathrm{C} 3$ and $\mathrm{C} 4$ loci, and the amygdala at the T3 and T4 loci.

Novik and Smirnov [11] studied the effect of geomagnetic storms at the latitude of Moscow on the electric oscillations of the human brain cerebral cortex. In course of electroencephalogram measurements it was shown that when the voluntary persons at the age of 18-23 years old were performing tasks using a computer during moderate magnetic storm or no later than $24 \mathrm{~h}$ after it, the value of the coherence function of electric oscillations of the human brain in the frontal and occipital areas in a range of 4,0-7,9 Hz (the theta rhythm) decreased by a factor of two or more, sometimes reaching zero, although arterial blood pressure, respiratory rate and the electrocardiogram registered during electroencephalogram measurements remained within the standard values.

Previously, Persinger and Richards [14] reported that a cluster of experiences loaded on a factor dominated by vestibular sensations significantly increased when global geomagnetic activity exceeded 15-20 nT. The two frequency bands most consistently and strongly correlated with increased geomagnetic activity within the range that occurred during their study were gamma $(35-45 \mathrm{~Hz})$ and theta $(4-7 \mathrm{~Hz})$. Mulligan et al [10] believe that a most parsimonious explanation for an intrinsic connection between these two nonadjacent bands involves a role of the hippocampal formation. These two bands involve the peak energy of the septal-hippocampal inputs. In addition, an intrinsic feature of many hippocampal neurons is the superimposition of gamma patterns upon the predominantly 5-7 Hz theta rhythm [18]. That the hippocampal formation, along with 
the amygdala, has the lowest threshold for seizure induction is well known [19]. The second environmental measure, atmospheric power, revealed similar effects. Again the cerebral region most consistently correlated with this inference of energy between the ionosphere and the Earth's surface was the right frontal lobe. Atmospheric power, measured in Gigawatts, reveals the consequences of the interactions between energetic particulates within the Earthionospheric cavity. This is a potentially important ancillary measure for electroencephalographic correlations because magneto-hydrodynamic waves generated within this medium can propagate to the Earth's surface. In both Experiments I and II the correlation between power within the gamma range and either geomagnetic activity or atmospheric power was negative. This means that as the geomagnetic activity or atmospheric power increased the cerebral activity within this band decreased [10].

Developing the discussion, Mulligan et al [10] appeal to the position that the right frontal area has powerful functional, primarily inhibitory, connections with the right parietal and temporal regions. Consequently, diminished power or inhibitory frontal functions can encourage disinhibition of functions within the caudal region. The resultant stimulation of activity would produce a sympathetic dominance (arousal), the phenomena that was also shown by Babayev and Allahverdiyeva [9] during moderate magnetic storms.

It is here that we consider it appropriate to make a small excursion. According to the concept of "central autonomic network (CAN)" [20-22] its include following cortical, subcortical, and medullary structures: the anterior cingulate, insular, orbitofrontal, and ventromedial cortices; the central nucleus of the amygdala; the paraventricular and related nuclei of the hypothalamus; the periaqueductal gray matter; the nucleus of the solitary tract; the nucleus ambiguous; the ventrolateral medulla; the ventromedial medulla and the medullary tegmental field. The primary output of the CAN is mediated through the preganglionic sympathetic and parasympathetic neurons, which exert control over the heart via the stellate ganglia and the vagus nerve, respectively. The interplay of sympathetic and parasympathetic influences on sinoatrial node pacemaker activity generates the complex variability that characterizes the healthy heart rate rhythm, which is called HRV. A fundamental principle of the neural control of the heart is its hierarchical organization, with cortical structures providing inhibitory control over limbic and brainstem sympathoexcitatory, cardioacceleratory circuits. Indeed, disruption of prefrontal activity leads to disinhibition of sympathoexcitatory circuits, with a resultant increase in heart rate and decrease in vagally-mediated HRV [23,24]. Furthermore, left-sided (dominant hemisphere) forebrain structures appear to be predominantly involved in vagal regulation, whereas homotopic right (nondominant) forebrain regions seem to primarily control sympathetic tone and responses [25,26]. However, the lateralization model of autonomic control of the heart remains controversial [27-29].

If the disturbances of the Earth's magnetic field are an obvious causal factor, then we are tormented by doubts about its first target (acceptor). Accepting the hypothesis of Limansky [4,5] and the concept of nervousness, we conclude that caused by geomagnetic disturbances changes in the conductivity of APs in one way or another (through afferent cutaneous nerves or liquid crystalline collagen fibers of the connective tissues $[30,31]$ ) reach medullary, subcortical and cortical structures of CAN, exciting some neurons and inhibiting others, thus 
triggering well-studied mechanisms of neuro-immune, neuro-endocrine and endocrine-immune modulation [32-42] documented in our study.

If we accept the paradigm of Eastern medicine, the information from APs enters the Chakras, which regulate the neuroendocrine-immune complex. The reality of this assumption is evidenced by the parameters of GDV (biophotonics), registered in the same observed individuals. But this will be discussed in a separate article.

Mulligan et al [10] suggest that direct geomagnetic effects on electroencephalographic activity can be reduced to the essential congruence of the magnitude of energy density within the human brain and the geomagnetic field. Their calculations showed that a shift of geomagnetic activity of only $25 \mathrm{nT}$ has the potential to change the energy available within the brain. Consequently, either the change in atmospheric power or the increase in geomagnetic intensity within this range would provide comparable changes in energy within the brain volume. Of course this is not a proof that energy absorption within the brain occurs from changes in either geomagnetic activity or atmospheric power.

According to Nordmann et al [43], there are 3 prevailing proposals being weighed regarding how magnetic fields are sensed by animals. First is provocation of action potentials in neurons by electromagnetic induction; second is light-sensitive, chemical-based mechanism mediated by cryptochromes resulting in action potentials as nervous signals [44-49]; and third is magnetite-based magnetoreceptors mechanically spotting the magnetic field, leading to neuronal action potentials [5054].
Therefore, the brain can directly accept geomagnetic disturbances, without the mediation of APs, followed by neuroendocrine and neuro-immune modulation. If this is accepted, then the changes in the electrical conductivity of APs detected by us should be considered as a consequence of the well-known skin-galvanic reflex caused by brain stimulation geomagnetic disturbances.

Simko and Mattsson [55] envisage that electromagnetic field (EMF) exposure can cause both acute and chronic effects that are mediated by increased free radical levels. Firstly, direct activation of, for example macrophages (or other cells) by short-term exposure to EMF leads to phagocytosis (or other cell specific responses) and consequently, free radical production. This pathway may be utilized to positively influence certain aspects of the immune response. Secondly, EMF-induced macrophage (cell) activation includes direct stimulation of free radical production.

Rosado et al [56] note, whereas the majority of the in vitro studies focused on monocytes/macrophages and fibroblasts, the effects of the exposure to EMF on other cell types are not well defined. In macrophages, the reduction in pro-inflammatory cytokines induced by EMF is associated with the activation of regulatory mechanisms induced by a moderate oxidative stress. However, in the case of neutrophils, activation of oxidative stress by EMF induces activation of NETosis.

However, this information is not entirely appropriate for our discussion, because the applied EMFs had a power comparable to that of the Earth's magnetic field or even greater. Only two studies of Selmaoui et al $[57,58]$ is noteworthy. The authors showed that exposure to $50-\mathrm{Hz}$ magnetic fields (10 $\mu \mathrm{T})$ significantly increases IL-6 when subjects were exposed to an intermittent 
magnetic field. However, no effect has been observed on interleukin IL-1 $\beta$, IL-2, IL1RA, and IL-2R. No significant differences were observed between sham-exposed (control) and exposed men for hemoglobin concentration, hematocrit, red blood cells, platelets, total leukocytes, monocytes, lymphocytes, eosinophils, or neutrophils. Immunologic variables (CD3, CD4, CD8, $\mathrm{NK}$ and $\mathrm{B}$ cells) were unaltered.

Therefore, the initial acceptance of geomagnetic disturbances by immunocytes is possible, but unlikely.

Recently, Gorgo et al [59] found the inverse proportional reliable average correlation between the values of specific bacterial luminescence and the $\mathrm{Kp}(\mathrm{r}=-0,41)$ as well as Ap $(r=-0,41)$ indexes of the geomagnetic field. Surprising is the proximity of the force of influence of the intensity of variations of the magnetic field on the day of testing (Ap0) both on the manifestation of bacterial activity and phagocytic function of neutrophils against bacteria [2]. This, in our opinion, confirms the direct effect of the geomagnetic field disturbances on human neutrophils. The decrease in the level of T-helpers and Blymphocytes reflects, in our opinion, the weakening of their expression of CD4 and CD22 receptors, respectively, as evidenced by the positive correlation of the Ap-index with the level of 0-lymphocytes [2].

Assuming the hypothesis that immunocytes are the primary target of geomagnetic disturbances, we have reason to speculate that the detected changes in EEG parameters are caused by released immunocytes, primarily macrophages, cytokines, hormones and neurotransmitters $[32,33]$.

Finally, the hypothesis that phagocytosis inhibition of two types of microbes found in our study [2] may be due to the positive effects of geomagnetic disturbances directly on bacteria (for example bacteria Photobacterium phosphoreum [59]), which are known to be able to actively counteract the bactericidal properties of phagocytes and other immunocytes [60], is not disqualified.

\section{Conclusion}

Disturbances of the geomagnetic field (Ap-index) causes a significant immediate modulating effect on the parameters of immunity as well as EEG, apparently through acupuncture points as polymodal receptors of the ecoceptive sensitivity system.

\section{Acknowledgment}

We express our sincere gratitude to administration of clinical sanatorium "Moldova" (Truskavets') for help in carrying out testing as well as Danylo Mel'nyk for Ap-index monitoring.

Conflict of interest. For all authors any conflict of interests is absent.

\section{References}

1.Popovych IL, Gozhenko AI, Badiuk NS, Napierata M, Muszkieta R, Zukow W, Yanchij RI, Lapovets' NYe, Lapovets' LYe, Tserkovniuk RG, Akimova VM, Nahurna YV, Martianova OI, Vivchar RYa, Chendey IV, Ruzhylo SV. Relationships between geomagnetic Ap-index and parameters of the immunity in patients with multiple sclerosis and radiculopathies. Journal of Education, Health and Sport. 2021; 11(3): 77-90.

2.Tserkovniuk, R., Yanchij, R., Plyska, O., Kovbasnyuk, M., Chendey, I., HagnerDerengowska, M., Zukow, X., Kałużny, K., Muszkieta, R., \& Zukow, W. (2021). Relationships between geomagnetic Ap-index and parameters 
of the immunity in patients with neuroendocrine-immune complex dysfunction in former sportsmen. Journal of Education, Health and Sport, 11(7), 335-348.

3.Limansky YuP. Hypothesis about acupuncture points as polymodal receptors of the ecoceptive sensitivity system. Fiziol Zhurn. 1990; 36(4): 115-121. [in Russian].

4.Gulyar SA, Limansky YuP. Functional system of regulation of electromagnetic balance of organism: mechanisms of primary reception of electromagnetic waves of optical range. Fiziol Zhurn. 2003; 49(2): 3544. [in Ukrainian].

5.Popadynets' OO, Gozhenko AI, Zukow W, Popovych IL. Peculiarities of spectral parameters of EEG, HRV and routine parameters of immunity in patients with various levels of the entropy of EEG, HRV, immunocytogram and leukocytogram. Journal of Education, Health and Sport. 2019; 9(8): 617-636.

6.Popadynets' O, Gozhenko A, Badyuk N, Popovych I, Skaliy A, HagnerDerengowska $\mathrm{M}$, et al. Interpersonal differences caused by adaptogen changes in entropies of EEG, HRV, immunocytogram, and leukocytogram. Journal of Physical Education and Sport. 2020; 20(Suppl. 2): 982-999.

7.Gozhenko AI, Korda MM, Popadynets' OO, Popovych IL. Entropy, Harmony, Synchronization and their Neuroendocrine-immune Correlates. Odesa. Feniks; 2021: 232. [in Ukrainian].

8.Muehsam D, Ventura C. Life rhythm as a symphony of oscillatory patterns: electromagnetic energy and sound vibration modulates gene expression for biological signaling and healing. Glob Adv Health Med. 2014; 3(2): 4055. doi:10.7453/gahmj.2014.008.
9.Babayev ES, Allahverdiyeva AA. Effects of geomagnetic activity variations on the physiological and psychological state of functionally healthy humans: some of results of the Azerbijani studies. Advances in Space Research. 2007; 40: 1941-1951.

10.Mulligan BP, Hunter MD, Persinger MA. Effects of geomagnetic activity and atmospheric power variations on quantitative measures of brain activity: replication of the Azerbaijani studies. Advances in Space Research. 2010; 45: 940-948.

11. Novik OB, Smirnov FA. Geomagnetic storm decreases coherence of electric oscillations of human brain while working at the computer. Biofizika. 2013;58(3):554-560.

12.Baevsky RM, Petrov VM, Cornelissen G, Halberg F, Orth-Gomer K, Akerstedt T, Otsuka K, Breus T, Siegelova J, Dusek J, Fiser B. Meta-analyzed heart rate variability, exposure to geomagnetic storms, and the risk of ischemic heart disease. Scr Med (Brno). 1997; 70(4-5): 201-206.

13.McCraty $\mathrm{R}$, Atkinson $\mathrm{M}$, Stolc $\mathrm{V}$, Alabdulgader AA, Vainoras A, Ragulskis M. Synchronization of Human Autonomic Nervous System Rhythms with Geomagnetic Activity in Human Subjects. International journal of environmental research and public health. 2017; 14(7): 770. https://doi.org/10.3390/ijerph1407077 0

14.Persinger MA, Richards PM. Vestibular experiences of humans during brief periods of partial sensory deprivation are enhanced when daily geomagnetic activity exceeds 15-20 nT. Neuroscience Letters. 1995; 194: 6972.

15.Cherry N. Schumann resonance, a plausible biophysical mechanism for the human health effects of 
solar/geomagnetic activity. Natural Hazards. 2002; 26: 279-331.

16.Schlegel K, Fuellekrug K. Schumann resonance parameter changesduring high-energy particle precipitation. Journal of Geophysical Research. 1999; 104(10):111-110.

17.Koenig HL, Krueger AP, Lang S, Sonning W. Biologic Effects of Environmental Electromagnetism. Springer-Verlag, New York, 1981.

18.Buzsaki G. Theta oscillations in the hippocampus. Neuron. 2002; 33:325340 ,

19.Gloor P. The Temporal Lobe and Limbic System. Oxford, New York,1997.

20.Benarroch EE. The central autonomic network: functional organization, dysfunction, and perspective. Mayo Clin Proc. 1993;68(10):988-1001. doi:10.1016/s0025-6196(12)62272-1

21.Palma JA, Benarroch EE. Neural control of the heart: recent concepts and clinical correlations. Neurology. 2014; 83: 261-271.doi: 10.1212/WNL.0000000000000605

22. Thayer JF, Lane RD. Claude Bernard and the heart-brain connection: further elaboration of a model of neurovisceral integration. Neurosci Biobehav Rev. 2009;33(2):81-88. doi:10.1016/j.neubiorev.2008.08.004

23.Verberne AJ. Medullary sympathoexcitatory neurons are inhibited by activation of the medial prefrontal cortex in the rat. Am J Physiol. 1996;270(4Pt2):R713-R719. doi:10.1152/ajpregu. 1996.270.4.R713

24.Verberne AJ, Lam W, Owens NC, Sartor D. Supramedullary modulation of sympathetic vasomotor function. Clin Exp Pharmacol Physiol. 1997;24(910):748-754. doi:10.1111/j.14401681.1997.tb02126.x

25.Guo CC, Sturm VE, Zhou J, Gennatas ED, Trujillo AJ, Hua AY, et al. Dominant hemisphere lateralization of cortical parasympathetic control as revealed by frontotemporal dementia. Proc Natl Acad Sci USA. 2016;113:E2430-E2439. doi: 10.1073/pnas.1509184113.

26. Winkelmann T, Thayer JF, Pohlack S, Nees F, Grimm O, Flor H. Structural brain correlates of heart rate variability in a healthy young adult population. Brain Struct Funct. 2017;222(2):10611068. doi:10.1007/s00429-016-1185-1

27. Thayer J F, Áhs F, Fredrikson M, Sollers JJ III, Wager TD. A meta-analysis of heart rate variability and neuroimaging studies: implications for heart rate variability as a marker of stress and health. Neurosci Biobehav Rev. 2012;36:747-756. doi: 10.1016/j.neubiorev.2011.11.009

28. Yoo HJ, Thayer JF, Greening S, Lee TH, Ponzio A, Min J, Sakaki M, Nga L, Mather M, Koeniget J. Brain structural concomitants of resting state heart rate variability in the young and old: evidence from two independent samples. Brain Struct Funct. 2018;223(2):727-737. doi:10.1007/s00429-017-1519-7

29.Carnevali L, Koenig J, Sgoifo A, Ottaviani C. Autonomic and Brain Morphological Predictors of Stress Resilience Front Neurosci. 2018; 12: 228.

30.Ho MW, Knight DP. The acupuncture system and the liquid crystalline collagen fibers of the connective tissues. Am J Chin Med. 1998;26(34):251-263.

31.Langevin HM. Connective tissue: a body-wide signaling network? Med Hypotheses. 2006;66(6):1074-1077.

32.Tracey KJ. Physiology and immunology of the cholinergic antiinflammatory pathway. J Clin Invest. 2007; 117(2): 289-296.

33.Thayer JF, Sternberg EM. Neural aspects of immunomodulation: Focus on the 
vagus nerve. Brain Behav Immun. 2010; 24(8): 1223-1228.

34.Popovych IL, Lukovych YuS, Korolyshyn TA, Barylyak LG, Kovalska LB, Zukow W. Relationship between the parameters heart rate variability and background EEG activity in healthy men. Journal of Health Sciences. 2013; 3(4): 217-240.

35.Popovych IL, Kozyavkina OV, Kozyavkina NV, Korolyshyn TA, Lukovych YuS, Barylyak LG. Correlation between Indices of the Heart Rate Variability and Parameters of Ongoing EEG in Patients Suffering from Chronic Renal Pathology. Neurophysiology. 2014; 46(2): 139148.

36.Kul'chyns'kyi AB, Kovbasnyuk MM, Kyjenko VM., Zukow W, Popovych IL. Neuro-immune relationships at patients with chronic pyelonephrite and cholecystite. Communication 2. Correlations between parameters EEG, HRV and Phagocytosis. Journal of Education, Health and Sport. 2016; 6(10): 377-401.

37.Kul'chyns'kyi AB, Gozhenko AI, Zukow W, Popovych IL. Neuro-immune relationships at patients with chronic pyelonephrite and cholecystite. Communication 3. Correlations between parameters EEG, HRV and Immunogram. Journal of Education, Health and Sport. 2017; 7(3): 53-71.

38.Kul'chyns'kyi AB, Kyjenko VM, Zukow W, Popovych IL. Causal neuroimmune relationships at patients with chronic pyelonephritis and cholecystitis. Correlations between parameters EEG, HRV and white blood cell count. Open Medicine. 2017; 12(1): 201-213.

39.Kul'chyns'kyi AB, Zukow W, Korolyshyn TA, Popovych IL. Interrelations between changes in parameters of HRV, EEG and humoral immunity at patients with chronic pyelonephritis and cholecystitis. Journal of Education, Health and Sport. 2017; 7(9): 439-459.

40.Popovych IL, Kul'chyns'kyi AB, Korolyshyn TA, Zukow W. Interrelations between changes in parameters of HRV, EEG and cellular immunity at patients with chronic pyelonephritis and cholecystitis. Journal of Education, Health and Sport. 2017; 7(10): 11-23.

41.Popovych IL, Kul'chyns'kyi AB, Gozhenko AI, Zukow W, Kovbasnyuk MM, Korolyshyn TA. Interrelations between changes in parameters of HRV, EEG and phagocytosis at patients with chronic pyelonephritis and cholecystitis. Journal of Education, Health and Sport. 2018; 8(2): 135-156.

42.Gozhenko AI, Zukow W, Polovynko IS, Zajats LM, Yanchij RI, Portnichenko VI, Popovych IL. Individual Immune Responses to Chronic Stress and their Neuro-Endocrine Accompaniment. RSW. UMK. Radom. Torun; 2019: 200.

43.Nordmann GC, Hochstoeger T, Keays DA. Unsolved mysteries: magnetoreception - A sense without a receptor. PLoS Biol. 2017;15(10): e2003234.

44.Gegear RJ, Casselman A, Waddell S, Reppert SM. Cryptochrome mediates light-dependent magnetosensitivity in Drosophila. Nature. 2008;454(7207):1014-1018. https://doi.org/10.1038/nature07183

45.Foley L, Gegear R, Reppert S. Human cryptochrome exhibits light-dependent magnetosensitivity. Nat Commun. 2011;2:356.

https://doi.org/10.1038/ncomms1364

46.Zaporozhan V, Ponomarenko A. Mechanisms of geomagnetic field influence on gene expression using 
influenza as a model system: basics of physical epidemiology. Int $\mathbf{J}$ Environ Res Public Health. 2010;7(3):938-965. doi:10.3390/ijerph7030938.

47.Hammad M, Albaqami M, Pooam M, Kernevez E, Witczak J, Ritz T, Martino C, Ahmad M. Cryptochrome mediated magnetic sensitivity in Arabidopsis occurs independently of light-induced electron transfer to the flavin. Photochemical Photobiological Sciences. 2020;19(3): 341-352. https://doi.org/10.1039/c9pp00469f

48.Cifra M, Apollonio F, Liberti M, GarcíaSánchez T, Mir LM. Possible molecular and cellular mechanisms at the basis of atmospheric electromagnetic field bioeffects. International journal of biometeorology. 2021; 65(1):59-67. https://doi.org/10.1007/s00484-02001885-1

49.Wan G, Hayden AN, Iiams SE, Merlin C. Cryptochrome 1 mediates lightdependent inclination magnetosensing in monarch butterflies. Nature communications. 2021;12(1):771. https://doi.org/10.1038/s41467-02121002-z

50.Kirschvink JL, Kobayashi-Kirschvink A, Woodford BJ. Magnetite biomineralization in the human brain. Proc Natl Acad Sci USA. 1992;89(16):7683-7687. doi: 10.1073 /pnas.89. 16. 7683.

51.Kirschvink JL, Kobayashi-Kirschvink A, Diaz-Ricci JC, Kirschvink SJ. Magnetite in human tissues: a mechanism for the biological effects of weak ELF magnetic fields. Bioelectromagnetics. 1992; Suppl 1: 101-113.

52.Kirschvink JL, Walker MM, Diebel CE. Magnetite-based magnetoreception.
Curr Opin Neurobiol. 2001;11(4):462467.

53.Winklhofer M, Kirschvink JL. A quantitative assessment of torquetransducer models for magnetoreception. JRSocInterface. 2010;7(supp1_2):S273-S289.

54.Gilder SA, Wack M, Kaub L, Roud SC, Petersen N, Heinsen $\mathrm{H}$, et al. Distribution of magnetic remanence carriers in the human brain. Sci. Rep. 2018;8(1):1-9.

55.Simko M, Mattsson MO. Extremely low frequency electromagnetic fields as effectors of cellular responses in vitro: possible immune cell activation. J Cell Biochem. 2004;93(1):83-92. doi: 10.1002/jcb.20198.

56.Rosado MM, Simkó M, Mattsson MO, Pioli C. Immune-Modulating Perspectives for Low Frequency Electromagnetic Fields in Innate Immunity. Frontiers in public health. 2018;6:85.

https://doi.org/10.3389/fpubh.2018.00085

57.Selmaoui B, Bogdan A, Auzeby A, Lambrozo J, Touitou Y. Acute exposure to $50 \mathrm{~Hz}$ magnetic field does not affect hematologic or immunologic functions in healthy young men: a circadian study. Bioelectromagnetics. 1996;17(5):364-372.

58.Selmaoui B, Lambrozo J, Sackett-Lundeen L, Haus E, Touitou Y. Acute exposure to $50-\mathrm{Hz}$ magnetic fields increases interleukin-6 in young healthy men. J Clin Immunol. 2011; 31(6):1105-1111. doi:10.1007/s10875-0119558-y

59.Gorgo YuP, Greckiy IO, Demydova OI. The use of luminos bacteria Photobacterium phosphoreum as a bioindicator of geomagnetic activity. Innov Biosyst Bioeng. 2018;2(4):271277. doi:10.20535/ibb.2018.2.4.151459.

60.Uribe-Querol E, Rosales C. Control of Phagocytosis by Microbial Pathogens. Front Immunol. 2017;8:1368. doi:10.3389/fimmu.2017.01368. 
Table 1. Matrix of correlations between Ap-Indices and EEG parameters

\begin{tabular}{|c|c|c|c|c|c|c|c|c|}
\hline Variables & Ap-7 & Ap-6 & Ap-5 & Ap-4 & Ap-3 & Ap-2 & Ap-1 & Ap0 \\
\hline PSD C $4-\theta, \%$ & 0,09 & 0,10 & 0,05 & 0,25 & 0,28 & 0,06 & $-0,30$ & $-0,30$ \\
\hline PSD C $3-\theta, \%$ & 0,01 & 0,05 & 0,10 & 0,25 & 0,25 & 0,08 & $-0,28$ & $-0,28$ \\
\hline PSD T6- $\theta, \%$ & $-0,03$ & 0,15 & 0,03 & 0,25 & 0,23 & 0,07 & $-0,29$ & $-0,26$ \\
\hline PSD C4- $\theta, \mu V^{2} / H z$ & 0,02 & $-0,00$ & $-0,16$ & $-0,05$ & 0,01 & $-0,18$ & $-0,27$ & $-0,26$ \\
\hline PSD T4- $\theta, \%$ & 0,16 & 0,10 & $-0,11$ & 0,14 & 0,20 & 0,01 & $-0,26$ & $-0,23$ \\
\hline PSD F7- $\theta, \%$ & 0,12 & 0,19 & $-0,11$ & 0,13 & 0,21 & $-0,05$ & $-0,30$ & $-0,21$ \\
\hline PSD F8- $\theta, \%$ & $-0,06$ & $-0,04$ & $-0,20$ & 0,06 & 0,06 & $-0,07$ & $-0,19$ & $-0,27$ \\
\hline PSD F4- $\theta, \mu V^{2} / H z$ & $-0,03$ & 0,06 & $-0,04$ & $-0,00$ & 0,07 & $-0,14$ & $-0,27$ & $-0,22$ \\
\hline PSD F4- $\theta, \%$ & 0,03 & 0,02 & 0,02 & 0,19 & 0,18 & 0,08 & $-0,24$ & $-0,25$ \\
\hline PSD Fp1- $\theta, \%$ & $-0,05$ & 0,13 & $-0,08$ & 0,11 & 0,09 & 0,02 & $-0,26$ & $-0,16$ \\
\hline PSD P4- $\theta, \mu V^{2} / H z$ & $-0,01$ & $-0,02$ & $-0,11$ & 0,07 & 0,09 & $-0,07$ & $-0,20$ & $-0,25$ \\
\hline PSD T6- $\alpha, \mu V^{2} / H z$ & $-0,10$ & $-0,18$ & $-0,13$ & $-0,02$ & $-0,02$ & $-0,11$ & $-0,13$ & $-0,25$ \\
\hline PSD O2- $\theta, \%$ & 0,15 & 0,14 & $-0,10$ & 0,18 & 0,23 & 0,08 & $-0,15$ & $-0,17$ \\
\hline PSD F8 $\delta, \mu V 2 / H z$ & 0,08 & 0,02 & 0,30 & 0,15 & 0,15 & 0,09 & $-0,14$ & $-0,06$ \\
\hline PSD T6- $\delta, \mu V 2 / H z$ & $-0,05$ & $-0,04$ & 0,27 & 0,09 & 0,07 & 0,06 & $-0,07$ & $-0,04$ \\
\hline PSD Fp1- $\delta, \mu \mathrm{V} 2 / \mathrm{Hz}$ & $-0,01$ & $-0,02$ & 0,21 & 0,04 & 0,04 & 0,03 & $-0,06$ & $-0,03$ \\
\hline PSD 02- $\beta, \mu \mathrm{V} 2 / \mathrm{Hz}$ & $-0,05$ & $-0,07$ & $-0,26$ & $-0,20$ & $-0,20$ & $-0,14$ & 0,07 & 0,04 \\
\hline Amplitude $\beta, \mu \mathrm{V}$ & 0,11 & 0,10 & $-0,23$ & $-0,17$ & $-0,10$ & $-0,08$ & 0,11 & 0,15 \\
\hline Entropy PSD O2 & 0,21 & 0,15 & $-0,24$ & 0,02 & 0,06 & $-0,01$ & $-0,03$ & 0,00 \\
\hline PSD F3- $\beta, \mu V 2 / \mathrm{Hz}$ & 0,26 & 0,29 & $-0,20$ & $-0,15$ & 0,02 & $-0,07$ & 0,06 & 0,18 \\
\hline PSD F3- $\beta, \%$ & 0,23 & 0,24 & $-0,13$ & $-0,02$ & 0,03 & $-0,04$ & 0,02 & 0,18 \\
\hline PSD C $3-\beta, \%$ & 0,14 & 0,27 & $-0,18$ & $-0,14$ & $-0,04$ & $-0,03$ & 0,24 & $\mathbf{0 , 3 0}$ \\
\hline PSD T5- $\theta, \%$ & 0,17 & $\mathbf{0 , 2 7}$ & $-0,04$ & 0,06 & 0,17 & $-0,03$ & $-0,14$ & $-0,00$ \\
\hline PSD F7- $\delta, \%$ & $-0,15$ & $-0,22$ & 0,02 & $-0,06$ & $-0,05$ & 0,13 & 0,12 & $-0,06$ \\
\hline Multiple correlation $\mathbf{R}$ & $\mathbf{0 , 3 9 0}$ & 0,713 & 0,670 & 0,539 & 0,482 & 0,294 & 0,736 & 0,687 \\
\hline
\end{tabular}

Table 2. Factor Structure Matrix for Canonical Roots of Ap-Indices and EEGs parameters

\begin{tabular}{|c|c|}
\hline Left set & $\mathbf{R}$ \\
\hline Ap-1, nT & $-0,252$ \\
\hline $\mathrm{Ap}-0, \mathrm{nT}$ & $-0,095$ \\
\hline Ap-2, nT & $-0,068$ \\
\hline $\mathrm{Ap}-5, \mathrm{nT}$ & $-0,667$ \\
\hline $\mathrm{Ap}-4, \mathrm{nT}$ & $-0,293$ \\
\hline Ap-3, nT & $-0,022$ \\
\hline $\mathrm{Ap}-7, \mathrm{nT}$ & 0,264 \\
\hline Ap-6, nT & 0,144 \\
\hline Right set & $\mathbf{R}$ \\
\hline PSD F7- $\theta, \%$ & 0,510 \\
\hline PSD F8- $\theta, \%$ & 0,440 \\
\hline PSD C4- $\theta, \mu V^{2} / H z$ & 0,431 \\
\hline PSD C $4-\theta, \%$ & 0,228 \\
\hline PSD Fp1- $\theta, \%$ & 0,342 \\
\hline PSD $\mathrm{F} 4-\boldsymbol{\theta}, \boldsymbol{\mu} \mathrm{V}^{2} / \mathrm{Hz}$ & 0,337 \\
\hline PSD F4- $\theta, \%$ & 0,176 \\
\hline PSD P4- $\theta, \mu V^{2} / H z$ & 0,320 \\
\hline PSD T6- $\theta, \%$ & 0,223 \\
\hline PSD O2- $\theta, \%$ & 0,316 \\
\hline PSD C $3-\theta, \%$ & 0,132 \\
\hline PSD T4- $\theta, \%$ & 0,130 \\
\hline PSD T6- $\alpha, \mu V^{2} / H z$ & 0,235 \\
\hline PSD $\mathrm{T} 6-\delta, \mu \mathrm{V}^{2} / \mathrm{Hz}$ & $-0,288$ \\
\hline
\end{tabular}




\begin{tabular}{|l|l|}
\hline PSD F8- $\delta, \mu \mathbf{V}^{2} / \mathrm{Hz}$ & $-\mathbf{0 , 2 6 3}$ \\
\hline PSD Fp1- $\boldsymbol{\delta}, \boldsymbol{\mu} \mathbf{V}^{2} / \mathrm{Hz}$ & $-\mathbf{0 , 2 1 8}$ \\
\hline Entropy PSD O2 & $\mathbf{0 , 3 5 1}$ \\
\hline Amplitude $\boldsymbol{\beta}, \boldsymbol{\mu V}$ & $\mathbf{0 , 2 4 9}$ \\
\hline PSD O2- $\boldsymbol{\beta}, \boldsymbol{\mu} \mathbf{V}^{2} / \mathrm{Hz}$ & $\mathbf{0 , 2 4 0}$ \\
\hline PSD F3- $\boldsymbol{\beta}, \boldsymbol{\mu} \mathbf{V}^{2} / \mathrm{Hz}$ & $\mathbf{0 , 3 6 1}$ \\
\hline PSD F3- $\boldsymbol{\beta}, \%$ & $\mathbf{0 , 2 0 6}$ \\
\hline PSD C3- $\boldsymbol{\beta}, \%$ & $\mathbf{0 , 1 6 2}$ \\
\hline PSD T5- $\boldsymbol{\theta}, \%$ & $\mathbf{0 , 3 2 1}$ \\
\hline PSD F7- $\boldsymbol{\delta}, \%$ & $-\mathbf{0 , 1 2 1}$ \\
\hline
\end{tabular}

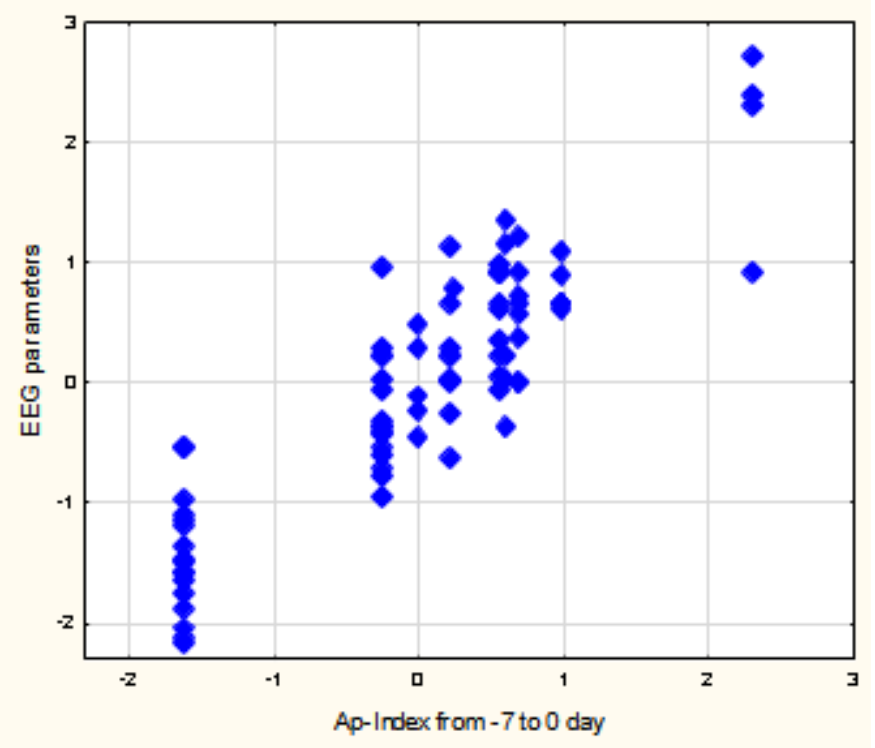

$\mathrm{R}=0,886 ; \mathrm{R}^{2}=0,786 ; \chi_{(280)}^{2}=347 ; \mathrm{p}=0,004 ; \Lambda$ Prime $=0,0028$

Fig. 1. Scatterplot of canonical correlation between Ap Geomagnetic indices before 7 days and on day testing (X-line) and EEG parameters (Y-line)

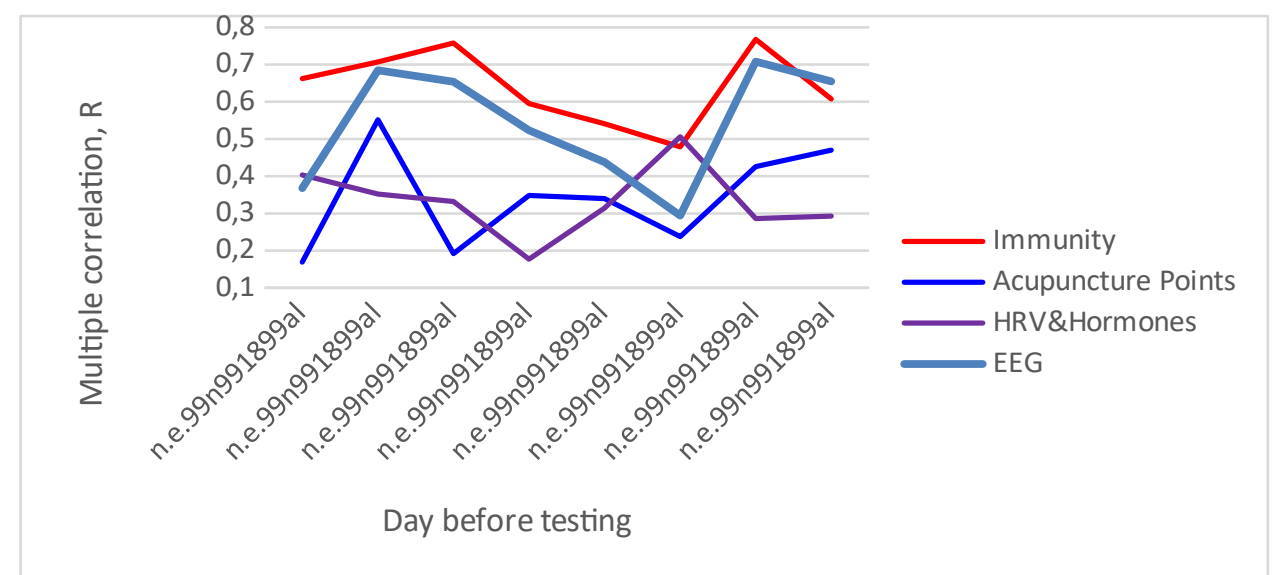

Fig. 2. Patterns of coefficients of multiple correlation $R$ between Ap-Indices and acupuncture points as well as neuro-endocrine-immune complex parameters 
Table 3. Factor Structure Matrix for first pair of Canonical Roots of EEG and Immune parameters

\begin{tabular}{|c|c|}
\hline Left set & R1 \\
\hline PSD $\mathrm{T} 6-\delta, \mu \mathrm{V}^{2} / \mathrm{Hz}$ & $-0,372$ \\
\hline PSD P4- $\beta, \%$ & $-0,335$ \\
\hline PSD T6- $\theta, \mu V^{2} / H z$ & $-0,286$ \\
\hline PSD T3- $\delta, \%$ & $-0,279$ \\
\hline PSD $\mathrm{F} 8-\delta, \mu \mathrm{V}^{2} / \mathrm{Hz}$ & $-0,269$ \\
\hline PSD F7 $\delta, \%$ & $-0,220$ \\
\hline PSD F7- $\beta, \mu V^{2} / H z$ & $-0,190$ \\
\hline PSD F8- $\theta, \mu V^{2} / H z$ & $-0,165$ \\
\hline PSD 02- $\theta, \%$ & 0,254 \\
\hline PSD T3- $\beta, \%$ & 0,220 \\
\hline PSD F4- $\theta, \%$ & 0,150 \\
\hline Right set & $\mathbf{R} 1$ \\
\hline Entropy of Immunocytogram & 0,549 \\
\hline CD22 ${ }^{+}$B-Lymphocytes, $\%$ & 0,532 \\
\hline Killing Index vs E. coli, \% & 0,329 \\
\hline Microbial Count for Staph. aureus, Bacter/Phag & 0,303 \\
\hline Immunoglobulins $\mathrm{M}, \mathrm{g} / \mathrm{L}$ & 0,269 \\
\hline $\mathrm{CD}^{+}{ }^{+} \mathrm{CD} 25^{+}$T-regulatory Lymphocytes, $\%$ & 0,247 \\
\hline Phagocytosis Index vs Staph. aureus, \% & 0,181 \\
\hline Bactericidal Capacity vs Staph. aureus, $10^{9} \mathrm{~B} / \mathrm{L}$ & 0,137 \\
\hline 0-Lymphocytes, \% & $-0,524$ \\
\hline Phagocytosis Index vs E. coli, \% & $-0,441$ \\
\hline
\end{tabular}

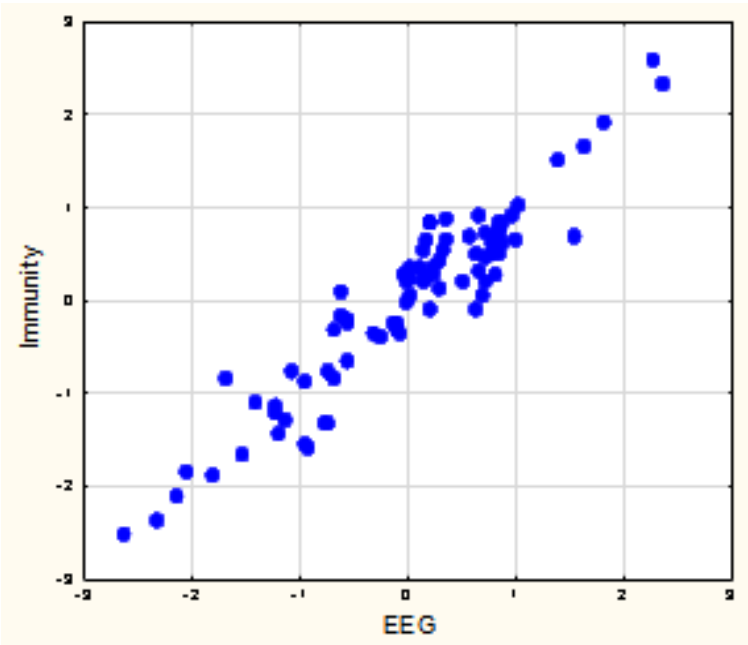

$\mathrm{R}=0,944 ; \mathrm{R}^{2}=0,892 ; \chi^{2}{ }_{(624)}=794 ; \mathrm{p}<10^{-5} ; \Lambda$ Prime $<10^{-6}$

Fig. 3. Scatterplot of canonical correlation between EEG (X-line) and Immunity (Y-line) parameters. First pair of Roots 
Table 4. Factor Structure Matrix for second pair of Canonical Roots of EEG and Immune parameters

\begin{tabular}{|c|c|}
\hline Left set & $\mathbf{R 2}$ \\
\hline PSD C $4-\theta, \%$ & 0,247 \\
\hline PSD T3- $\theta, \%$ & 0,247 \\
\hline PSD F3- $\beta, \%$ & 0,247 \\
\hline PSD F7- $\beta, \%$ & 0,239 \\
\hline PSD Fp1- $\theta, \%$ & 0,234 \\
\hline PSD C $3-\theta, \%$ & $\mathbf{0 , 2 2 5}$ \\
\hline PSD T6- $\beta, \%$ & 0,224 \\
\hline PSD F7- $\theta, \%$ & 0,220 \\
\hline PSD T $6-\theta, \%$ & 0,216 \\
\hline PSD T4- $\beta, \%$ & 0,215 \\
\hline PSD F8- $\theta, \%$ & 0,196 \\
\hline PSD F4- $\theta, \%$ & 0,185 \\
\hline PSD T6- $\delta, \mu V^{2} / H z$ & 0,145 \\
\hline PSD T3- $\beta, \%$ & 0,127 \\
\hline PSD T5- $\delta, \%$ & $-0,221$ \\
\hline PSD F7- $\delta, \%$ & $-0,203$ \\
\hline PSD T3- $\delta, \%$ & $-0,163$ \\
\hline Right set & $\mathbf{R 2}$ \\
\hline Immunoglobulins A, g/L & 0,383 \\
\hline Killing Index vs E. coli, \% & 0,340 \\
\hline $\mathrm{CD} 4{ }^{+} \mathrm{CD} 25^{+}$T-regulatory Lymphocytes, \% & 0,224 \\
\hline Bactericidal Capacity vs E. coli, $10^{9}$ Bacteria/L & 0,191 \\
\hline Immunoglobulins $\mathrm{M}, \mathrm{g} / \mathrm{L}$ & 0,185 \\
\hline
\end{tabular}

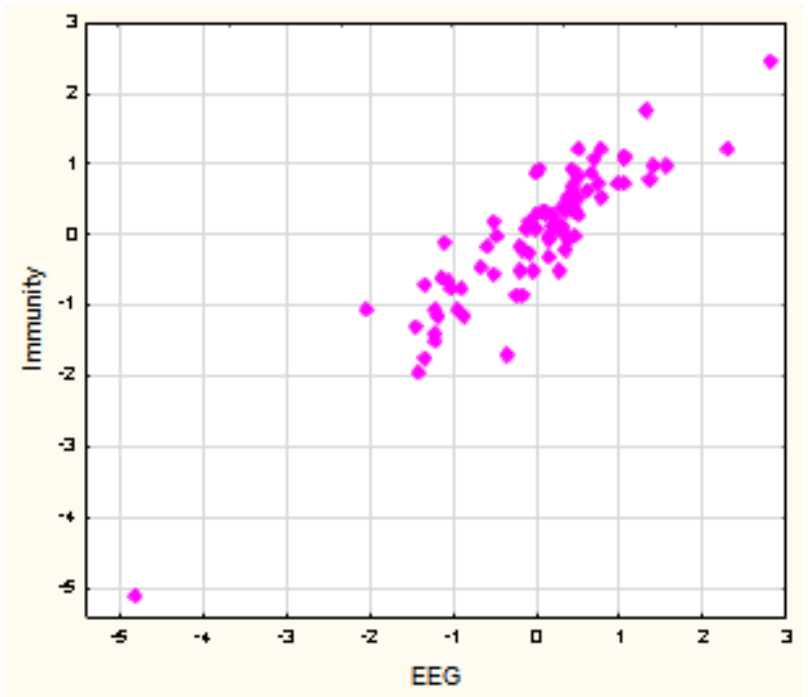

$\mathrm{R}=0,908 ; \mathrm{R}^{2}=0,824 ; \chi_{(570)}^{2}=676 ; \mathrm{p}=0,002 ; \Lambda$ Prime $<10^{-5}$

Fig. 4. Scatterplot of canonical correlation between EEG (X-line) and Immunity (Y-line) parameters. Second pair of Roots 